\title{
Comprehensive Evaluation of Tourism Development Potential in Anhui Province Based on Cluster Analysis and Factor Analysis
}

\author{
Xueyan Li, Xiaoxiao Zhan, Jinli Jiang \\ School of Statistics and Applied Mathematics, Anhui University of Finance and Economics, Bengbu, China \\ Email:XueyanLi@163.com
}

How to cite this paper: Li, X. Y., Zhan, X. X., \& Jiang, J. L. (2021). Comprehensive Evaluation of Tourism Development Potential in Anhui Province Based on Cluster Analysis and Factor Analysis. Open Journal of Business and Management, 9, 866-876. https://doi.org/10.4236/ojbm.2021.92046

Received: February 25, 2021

Accepted: March 28, 2021

Published: March 31, 2021

Copyright $\odot 2021$ by author(s) and Scientific Research Publishing Inc. This work is licensed under the Creative Commons Attribution International License (CC BY 4.0).

http://creativecommons.org/licenses/by/4.0/

\begin{abstract}
In order to improve the potential of urban tourism in Anhui Province, the comprehensive evaluation of the development level of urban tourism in Anhui Province is carried out. Firstly, the comprehensive evaluation index system of the development level of tourism is constructed. Secondly, 16 cities in Anhui Province are divided into four categories through cluster analysis, and Hefei has the best tourism development. Then factor analysis is carried out to get the ranking of each prefecture-level city. The top two cities in tourism development level are Hefei and Huangshan. Finally, the conclusion is that the tourism development level of 16 cities in Anhui Province is not balanced and the tourism industry is still to be developed.
\end{abstract}

\section{Keywords}

Tourism Potential, System Clustering, Factor Analysis, Anhui Province, Comprehensive Evaluation

\section{Introduction}

Nowadays, with the improvement of people's living standard, traveling has become a way to relax and experience life. Tourism can drive economic development. The tourism potential of a city is related to its transportation, accommodation, scenic spots, food, shopping and so on. The tourism economy of a city is an important part of the city economy.

The potential evaluation of urban tourism industry is to evaluate the potential tourism development strength of different cities in the future based on the data of various factors affecting the development of tourism in previous years. The development of tourism plays a vital role in the economic development of the 
region, so many scholars are quite interested in it and have carried out relevant exploration and research. In terms of the influencing factors of tourism development potential, YunCai Dong et al. calculated the tourism competitiveness based on the entropy value method and obtained the strong and weak relationship of the influencing factors of the urban tourism competitiveness (Dong \& $\mathrm{Wu}, 2016)$. In terms of the quantitative measurement of tourism competitiveness, ShiMin Fang et al. constructed the evaluation index system of tourism competitiveness, calculated the tourism competitiveness of eight cities and prefectures (forest regions) in the western Hubei circle with factor analysis method, and then analyzed the changes of tourism competitiveness in the last 10 years (Fang \& Lan, 2017). Ning Cao et al. analyzed the key factors affecting the size of tourism competitiveness, established an evaluation model of urban tourism competitiveness based on this, and finally reached the conclusion that there were differences between the camp division of tourism competitiveness of 14 cities in Liaoning Province and people's common sense objective understanding (Cao \& Guo, 2005). Nina Qu established an index system for the evaluation of tourism competitiveness, gave weight to the evaluation indexes by means of coefficient of variation and analytic hierarchy process, and evaluated the tourism competitiveness of the region by using a weighted summation multi-index comprehensive evaluation model (Qu, 2016). ShiCheng Deng conducted a comprehensive quantitative evaluation and comparative analysis on the tourism destination competitiveness of 38 districts and counties in Chongqing based on principal component analysis and K-means clustering analysis (Deng, 2020). In the analysis of tourism competitiveness, few studies combine cluster analysis with factor analysis. Based on this, this paper firstly clusters cities according to the tourism development level of 16 cities in Anhui Province, and then conducts factor analysis to comprehensively evaluate the tourism development potential of Anhui Province.

\section{Index Selection and Data Source}

\subsection{The Construction of Index System}

Factors of tourism impact range, the influence level of tourism development, involving multiple dimensions such as economy, society and environment, the evaluation index of the tourism industry potential is numerous, by consulting relevant literature, this article selects the including the potential demand of tourism, tourism supply potential, tourism potential support and guarantee of four aspects, such as potential 21 indicators, constructs the comprehensive evaluation index system of tourism industry potential, evaluation index as shown in Table 1.

\subsection{Data Source and Preprocessing}

The author selects 21 indicators from four aspects, including tourism demand 
potential, tourism supply potential, tourism support potential and tourism guarantee potential, to reflect the tourism industry potential of Anhui Province. The data comes from the Statistical Yearbook of Anhui Province in 2019, and all the data are true and effective. In order to eliminate the dimensionality effect, the data is normalized. Suppose there are $n$ objects and $p$ indexes. The value of the $j$ th index of the $i$ th object is $X_{i j}$, and the normalized index value is $X_{i j}^{*}$.

$$
\begin{gathered}
X_{i j}^{*}=\frac{X_{i j}-\bar{X}_{j}}{\sqrt{\operatorname{var}\left(X_{j}\right)}} \quad(i=1, \cdots, n ; j=1, \cdots, p) \\
\bar{X}_{j}=\frac{\sum_{i=1}^{n} X_{i j}}{n} . \\
\operatorname{var}\left(X_{j}\right)=\frac{\sum_{i=1}^{n}\left(X_{i j}-\bar{X}_{j}\right)^{2}}{n} .
\end{gathered}
$$

Among them, $\bar{X}_{j}$ is the mean of the ${ }^{\text {th }}$ index, $\operatorname{var}\left(X_{j}\right)$ is the variance of

\begin{tabular}{|c|c|c|}
\hline First level index & Second level index & Third level index \\
\hline & & Domestic tourism revenue/100 million yuan $\left(X_{1}\right)$ \\
\hline & & Foreign exchange income from international tourism/ten thousand dollars $\left(X_{2}\right)$ \\
\hline & & Per capita consumption of domestic tourism/yuan $\left(X_{3}\right)$ \\
\hline & Iourism demand potential & Average length of stay for domestic travel/day $\left(X_{4}\right)$ \\
\hline & & Domestic Tourist Numbers/ten thousand person $\left(X_{5}\right)$ \\
\hline & & number of inbound travelers/ten thousand person $\left(X_{6}\right)$ \\
\hline & & Number of A-class and above scenic spots/pcs $\left(X_{7}\right)$ \\
\hline & & Number of $4 \mathrm{~A}$ and above scenic spots/pcs $\left(X_{8}\right)$ \\
\hline & 1 & Number of tourist Rooms/pcs $\left(X_{10}\right)$ \\
\hline \multirow{10}{*}{$\begin{array}{c}\text { Tourism Industry } \\
\text { Potential }\end{array}$} & & Number of hotel beds/pcs $\left(X_{11}\right)$ \\
\hline & & Number of star hotels/pcs $\left(X_{12}\right)$ \\
\hline & & Gross domestic product (GDP)/100 million $\left(X_{13}\right)$ \\
\hline & & Per capita gross domestic product/yuan per person $\left(X_{14}\right)$ \\
\hline & Tourism support potential & The proportion of the tertiary industry in GDP/\% $\left(X_{15}\right)$ \\
\hline & & Per capita disposable income of urban residents/yuan $\left(X_{16}\right)$ \\
\hline & & Per capita disposable income of rural residents/yuan $\left(X_{17}\right)$ \\
\hline & & Highway passenger volume/ten thousand person $\left(X_{18}\right)$ \\
\hline & 1 & Per capita park green area/sq.m. $\left(X_{20}\right)$ \\
\hline & & Green space coverage in built-up areas/\% $\left(X_{21}\right)$ \\
\hline
\end{tabular}
the $x$ th index.

Table 1. Evaluation index system of tourism industry potential in Anhui Province. 


\section{Clustering Model of Tourism Industry Potential in Anhui Province}

\subsection{Research Thought}

Based on the comprehensive evaluation index data of tourism industry potential of 16 cities in Anhui Province, the 16 cities were divided into four categories according to the level of tourism development by systematic clustering method, and the tourism industry potential of the four categories of regions was analyzed.

\subsection{Research Method}

Systematic clustering method: according to the difference of distance between samples, the system clustering will cluster the samples with small distance into one category first, and the samples with large distance into one category later, until all the samples are clustered into a cluster. In the cluster analysis, the most common distance calculation formula is square Euclidean distance, so the square Euclidean distance will be selected to calculate the distance between samples, and its calculation formula is:

$$
d_{i j}=\sum_{k=1}^{p}\left|x_{i k}-x_{j k}\right|^{2} .
$$

Ward deviation sum of squares method: first, $\mathrm{n}$ samples are grouped into one class respectively, at this time, the sum of total deviation squares $S=0$, and then, according to the principle of minimizing the sum of total deviation squares, two of them are grouped into one class, and the cycle continues until all samples are grouped into one class.

$$
S_{t}=\sum_{i=1}^{n_{t}}\left(X_{i}^{(t)}-\bar{X}^{(t)}\right)^{\prime}\left(X_{i}^{(t)}-\bar{X}^{(t)}\right)
$$

\subsection{Analysis of Clustering Results}

According to the selected indicators of tourism demand potential, tourism supply potential and other aspects, the data of 2019 is clustering based on SPSS software, and the clustering results are shown in Figure 1.

According to Figure 1, 16 cities in Anhui Province can be divided into four categories. As shown in Table 2, Hefei is grouped into one category. Huangshan Mountain is grouped into a class; Maanshan, Wuhu, Lu'an, Xuancheng, Anqing and Chizhou are grouped together. Huaibei, Tongling, Bengbu, Huainan, Bozhou, Suzhou, Fuyang and Chuzhou are grouped in one group.

Table 2. Stratified clustering results of tourism industry potential of 16 cities in Anhui Province.

\begin{tabular}{cc}
\hline Category & area \\
\hline 1 & Hefei \\
2 & Huangshan \\
3 & Maanshan, Wuhu, Lu'an, Xuancheng, Anqing, Chizhou \\
4 & Huaibei, Tongling, Bengbu, Huainan, Bozhou, Suzhou, Fuyang, Chuzhou \\
\hline
\end{tabular}




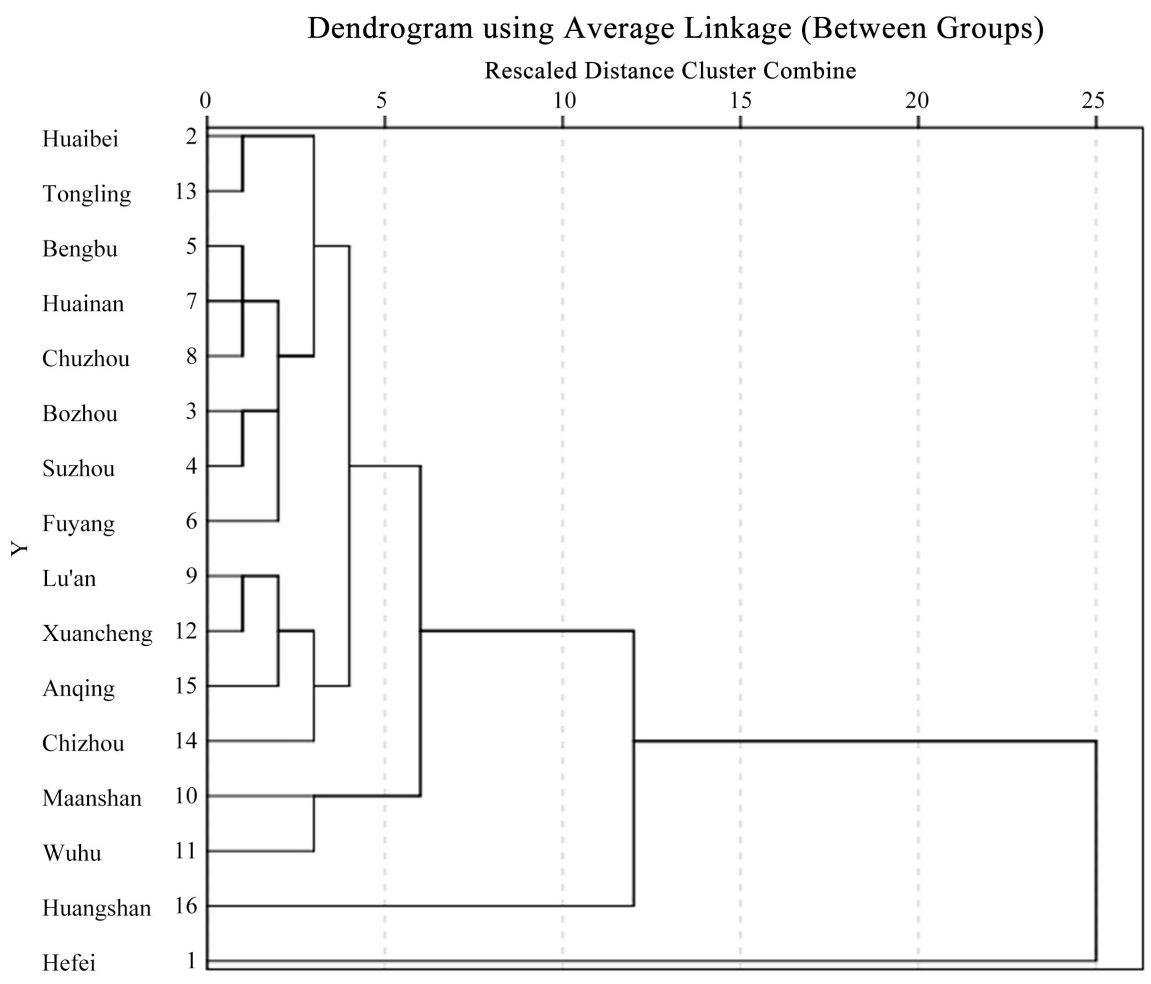

Figure 1. Systematic clustering genealogy of tourism industry potential of 16 cities in Anhui Province.

\section{Comprehensive Evaluation of Tourism Industry Potential in Anhui Province Based on Factor Analysis}

\subsection{Research Thought}

Factor analysis is to divide the variables with high correlation into a group, and the variables with low correlation into different groups. Each group of variables is represented by an implied comprehensive variable, which is the common factor. It reduces the dimensionality of multiple variables to a few principal factors, reflecting the correlation between original variables and principal factors.

\subsection{Research Method}

The idea of R-type factor analysis is to decompose each original variable into two parts: one part is composed of a few factors common to all variables, namely the so-called common factor part; the other part is the factor that each variable has alone, that is, the so-called unique factor part.

$$
X_{i}=u_{i 1} F_{1}+u_{i 2} F_{2}+\cdots+u_{i m} F_{m}+\varepsilon_{i} \quad(i=1,2, \cdots, p)
$$

Among them, $F_{1}, F_{2}$ and $F_{m}$ are common factors, and $\varepsilon_{i}$ is a special factor of $X_{i}$.

It can also be expressed in matrix form

$$
X=U F+\varepsilon .
$$

Among them, 


$$
\begin{gathered}
U=\left[\begin{array}{cccc}
u_{11} & u_{11} & \cdots & u_{1 m} \\
u_{12} & u_{22} & \cdots & u_{2 m} \\
\vdots & \vdots & \ddots & \vdots \\
u_{p 1} & u_{p 2} & \cdots & u_{p m}
\end{array}\right]=\left(U_{1}, U_{2}, \cdots, U_{m}\right) \\
X=\left(X_{1}, \cdots, X_{p}\right)^{\prime}, F=\left(F_{1}, \cdots, F_{m}\right)^{\prime}, \varepsilon=\left(\varepsilon_{1}, \cdots, \varepsilon_{p}\right)^{\prime} .
\end{gathered}
$$

where $U$ is the factor load matrix, and $u_{i j}$ is the load of the th variable on the th factor. The smaller $u_{i j}$ is, the smaller the correlation between the original variable and the common factor is, and vice versa.

\subsection{Interpretation of Result}

\section{1) KMO and Bartlett's sphericity test results}

As shown in Table 3, the KMO value of the model based on SPSS software is 0.792 , and the $\mathrm{P}$ value of Bartlett's test is $0.000(<0.01)$. Therefore, the null hypothesis should be rejected, the correlation between variables is strong, and the factor analysis is appropriate.

\section{2) Factoring}

In general, the number of common factors is determined according to the principle that the cumulative variance contribution rate is greater than $85 \%$. As shown in Table 4, the cumulative variance contribution rate of the first four principal components reached $88.041 \%$, and the variance contribution rates of each principal component were $54.05 \%, 18.22 \%, 10.04 \%$ and $5.73 \%$, respectively. Therefore, it was appropriate to extract four common factors. The four common factors are recorded as $F_{1}, F_{2}, F_{3}$ and $F_{4}$ respectively. The common factors contain $88.041 \%$ of the tourism development level of 16 cities in Anhui Province. The comprehensive evaluation of the tourism development level of Anhui Province after extracting the common factors has a good effect.

\section{3) Factor rotation and naming}

In order to make the component coefficient of the principal factor more reasonable and facilitate the interpretation of the meaning of each principal factor, the most commonly used method for the rotation of the principal factor is the orthogonal rotation method. The matrix after rotation is shown in Table 5.

As can be seen from Table 5, domestic tourism income, highway passenger volume, number of travel agencies and GDP and other indicators have a relatively high load on $F_{1}$, so the common factor $F_{1}$ can be named as the tourism demand potential factor. The number of inbound tourists, the number of star-rated hotels, the number of tourist rooms and the number of hotel beds have a higher load on $F_{2}$, so the common factor $F_{2}$ is named as the tourism supply potential factor. The evaluation indexes such as per capita GDP and per capita disposable income of rural residents have a higher load on $F_{3}$, so the common factor $F_{3}$ is named as the potential factor of tourism support. Evaluation indexes such as green coverage rate of built-up areas and per capita park green area have higher load on $F_{4}$, so the common factor $F_{4}$ is named as tourism 
security potential factor.

\section{4) Calculate factor score}

Then, the regression estimation method was used to calculate the factor score, and the coefficient matrix of each factor component was shown in Table 6.

According to the factor component coefficients in Table 6, the factor scoring function is obtained.

Table 3. KMO and Bartlett tests.

\begin{tabular}{lcr}
\hline & KMO sampling fitness measure & 0.792 \\
\hline & The approximate chi-square & 239.283 \\
Bartlett's test for sphericity & Degree of freedom & 66 \\
& significance & 0.000 \\
\hline
\end{tabular}

Table 4. Principal factor extraction and cumulative contribution rate.

\begin{tabular}{|c|c|c|c|c|c|c|c|c|c|}
\hline \multicolumn{10}{|c|}{ Total variance interpretation } \\
\hline \multirow[b]{2}{*}{ Element } & \multicolumn{3}{|c|}{ Initial eigenvalue } & \multicolumn{3}{|c|}{ Extract the sum of the squares of the load } & \multicolumn{3}{|c|}{ Sum of the squares of the rotational loads } \\
\hline & Aggregate & $\begin{array}{c}\text { Percentage of } \\
\text { variance }\end{array}$ & $\begin{array}{l}\text { Cumulative } \\
\text { percentage }\end{array}$ & Aggregate & $\begin{array}{l}\text { Percentage of } \\
\text { variance }\end{array}$ & $\begin{array}{l}\text { cumulative } \\
\text { percentage }\end{array}$ & Aggregate & $\begin{array}{l}\text { Percentage of } \\
\text { variance }\end{array}$ & $\begin{array}{l}\text { cumulative } \\
\text { percentage }\end{array}$ \\
\hline 1 & 10.819 & 54.045 & 54.045 & 10.819 & 54.045 & 54.045 & 6.715 & 32.736 & 32.736 \\
\hline 2 & 3.826 & 18.221 & 72.266 & 3.826 & 18.221 & 72.266 & 5.615 & 28.570 & 61.306 \\
\hline 3 & 2.109 & 10.044 & 82.309 & 2.109 & 10.044 & 82.309 & 3.426 & 16.312 & 77.618 \\
\hline 4 & 1.203 & 5.731 & 88.041 & 1.203 & 5.731 & 88.041 & 2.201 & 10.423 & 88.041 \\
\hline
\end{tabular}

Table 5. The composition matrix after rotation.

\begin{tabular}{|c|c|c|c|c|c|c|c|c|c|}
\hline \multirow{2}{*}{ Evaluation index } & \multicolumn{4}{|c|}{ Principal component } & \multirow{2}{*}{ Evaluation index } & \multicolumn{4}{|c|}{ Principal component } \\
\hline & 1 & 2 & 3 & 4 & & 1 & 2 & 3 & 4 \\
\hline$X_{1}$ & 0.782 & 0.597 & 0.167 & -0.033 & $X_{12}$ & 0.339 & 0.771 & 0.446 & -0.184 \\
\hline$X_{2}$ & 0.073 & 0.985 & -0.079 & 0.054 & $X_{13}$ & 0.742 & 0.613 & -0.232 & -0.115 \\
\hline$X_{3}$ & 0.639 & 0.561 & 0.264 & -0.174 & $X_{14}$ & 0.116 & 0.01 & 0.948 & 0.17 \\
\hline$X_{4}$ & 0.799 & 0.387 & -0.169 & -0.29 & $X_{15}$ & 0.454 & 0.748 & 0.214 & -0.034 \\
\hline$X_{5}$ & 0.808 & 0.511 & 0.249 & -0.053 & $X_{16}$ & 0.213 & 0.068 & 0.953 & 0.135 \\
\hline$X_{6}$ & 0.232 & 0.938 & -0.056 & 0.167 & $X_{17}$ & 0.191 & 0.245 & 0.925 & -0.193 \\
\hline$X_{7}$ & -0.015 & 0.877 & 0.254 & -0.341 & $X_{18}$ & 0.71 & 0.613 & -0.258 & -0.007 \\
\hline$X_{8}$ & -0.027 & 0.873 & 0.382 & 0.244 & $X_{19}$ & 0.748 & 0.613 & -0.187 & 0.008 \\
\hline$X_{9}$ & 0.823 & 0.463 & 0.267 & 0.128 & $X_{20}$ & -0.188 & -0.622 & -0.269 & 0.632 \\
\hline$X_{10}$ & 0.465 & 0.749 & 0.464 & -0.041 & $X_{21}$ & -0.091 & 0.258 & 0.448 & 0.824 \\
\hline$X_{11}$ & 0.38 & 0.727 & 0.567 & -0.028 & & & & & \\
\hline
\end{tabular}


Table 6. Component score coefficient matrix.

\begin{tabular}{|c|c|c|c|c|c|c|c|c|c|}
\hline \multirow{2}{*}{ Evaluation index } & \multicolumn{4}{|c|}{ Principal component } & \multirow{2}{*}{ Evaluation index } & \multicolumn{4}{|c|}{ Principal component } \\
\hline & 1 & 2 & 3 & 4 & & 1 & 2 & 3 & 4 \\
\hline$X_{1}$ & 0.101 & 0.025 & -0.031 & 0.044 & $X_{12}$ & 0.087 & -0.031 & 0.071 & -0.096 \\
\hline$X_{2}$ & -0.099 & 0.002 & 0.305 & -0.071 & $X_{13}$ & 0.069 & 0.084 & -0.122 & 0.009 \\
\hline$X_{3}$ & -0.007 & 0.085 & 0.052 & -0.099 & $X_{14}$ & -0.124 & 0.239 & 0.003 & 0.119 \\
\hline$X_{4}$ & 0.163 & -0.045 & -0.122 & -0.095 & $X_{15}$ & -0.013 & 0.004 & 0.193 & -0.063 \\
\hline$X_{5}$ & 0.111 & 0.000 & -0.009 & 0.024 & $X_{16}$ & -0.107 & 0.225 & 0.013 & 0.099 \\
\hline$X_{6}$ & -0.033 & -0.025 & 0.253 & 0.037 & $X_{17}$ & -0.176 & 0.235 & 0.114 & -0.163 \\
\hline$X_{7}$ & 0.195 & -0.154 & -0.003 & -0.166 & $X_{18}$ & 0.093 & 0.071 & -0.146 & 0.092 \\
\hline$X_{8}$ & 0.252 & -0.162 & -0.032 & 0.242 & $X_{19}$ & 0.077 & 0.084 & -0.123 & 0.093 \\
\hline$X_{9}$ & 0.146 & -0.019 & -0.029 & 0.157 & $X_{20}$ & 0.179 & -0.160 & -0.163 & 0.479 \\
\hline$X_{10}$ & 0.072 & 0.007 & 0.067 & 0.000 & $X_{21}$ & -0.038 & 0.092 & 0.070 & 0.526 \\
\hline$X_{11}$ & 0.068 & -0.009 & 0.099 & -0.004 & & & & & \\
\hline
\end{tabular}

$$
\begin{aligned}
& F_{1}=0.101 X_{1}-0.099 X_{2}-0.007 X_{3}+\cdots+0.077 X_{19}+0.179 X_{20}-0.038 X_{21} \\
& F_{2}=0.025 X_{1}+0.002 X_{2}+0.085 X_{3}+\cdots+0.084 X_{19}-0.160 X_{20}+0.092 X_{21} \\
& F_{3}=-0.031 X_{1}+0.305 X_{2}+0.052 X_{3}+\cdots-0.123 X_{19}-0.163 X_{20}+0.070 X_{21} \\
& F_{4}=0.044 X_{1}-0.071 X_{2}-0.099 X_{3}+\cdots+0.093 X_{19}+0.479 X_{20}+0.526 X_{21}
\end{aligned}
$$

Then, the comprehensive score of 16 cities in Anhui Province can be calculated. The weight is the ratio of the variance contribution rate of main factors to the total variance contribution rate. The scores of common factors and comprehensive scores of 16 cities in Anhui Province are shown in Table 7. The lower the comprehensive score is, the lower the level of tourism development and the weaker the potential of the city. On the contrary, the higher, the stronger.

From the perspective of the overall development level of Anhui tourism, the score is low, and the development potential of Anhui tourism is low. From the city point of view, the level of tourism development is uneven, the gap is larger. According to Table 7 and the categories divided by cluster analysis, Hefei is an area with strong development potential of tourism industry. Hefei has absolute competitive advantage in tourism development, and its comprehensive score is much higher than that of the other 15 cities. Compared with other cities in Anhui Province, Hefei has a fault type advantage in tourism industry potential. Among the 16 cities, the potential factors $F_{1}, F_{2}$ and $F_{3}$ of the tourism industry in Hefei ranked first, third and third respectively, that is, the potential of tourism demand, the potential of tourism supply, the potential of tourism support and the comprehensive strength ranked first. Hefei, known as "huai right inner pipes, jiangnan lips" reputation, has A long history of more than 2000 years, A 
level and above tourist attractions at 59, rich in tourism resources, including sanhe town is $5 \mathrm{~A}$ scenic spot, and emblem park and temple of outstanding scenic spots and historical sites, such as LaoShanDao scenic area and economy by leaps and bounds in recent years, by the reputation of "garden city" and "green city" of Hefei tourism development level in the advantage position (Luo et al., 2020). The tourism security potential factor $F_{4}$ is ranked the 10 th, mainly because Hefei is the capital city of Anhui Province, with a large population influx, but limited land resources and average green coverage rate. The large population leads to fewer tourism and living environment resources.

The area with strong tourism industry potential is Huangshan Mountain, whose tourist attractions are well known at home and abroad, complete tourism facilities and good services, and which is a key area supporting the development of Anhui tourism (Sun, 2014). Among them, Huangshan is the most famous tourism resources, Huangshan is the United Nations world cultural and natural heritage, renowned at home and abroad, is the first in the world, has also become the symbol of Anhui Province's tourism, Huangshan lays the foundation for the development of tourism.

Table 7. Comprehensive evaluation of tourism industry potential of each city in Anhui Province.

\begin{tabular}{|c|c|c|c|c|c|c|c|c|c|c|}
\hline \multirow{2}{*}{ Region } & \multicolumn{2}{|c|}{$F_{1}$} & \multicolumn{2}{|c|}{$F_{2}$} & \multicolumn{2}{|c|}{$F_{3}$} & \multicolumn{2}{|c|}{$F_{4}$} & \multicolumn{2}{|c|}{ Tourism Industry Potential } \\
\hline & score & ranking & score & ranking & score & ranking & score & ranking & synthesis score & ranking \\
\hline Hefei & 3.22 & 1 & 0.33 & 3 & 1.31 & 3 & -0.20 & 10 & 1.65 & 1 \\
\hline Huangshan & -0.69 & 14 & 30.03 & 1 & -0.09 & 7 & 0.09 & 7 & 0.62 & 2 \\
\hline Wuhu & -0.24 & 8 & 0.09 & 5 & 1.76 & 2 & -0.72 & 12 & 0.48 & 3 \\
\hline Anqing & 1.02 & 2 & 0.07 & 6 & -1.14 & 15 & 0.63 & 4 & 0.28 & 4 \\
\hline Chizhou & -0.55 & 13 & 1.31 & 2 & -0.28 & 9 & 1.08 & 2 & 0.20 & 5 \\
\hline Xuancheng & 0.05 & 4 & 0.15 & 4 & -0.22 & 8 & 0.50 & 5 & 0.14 & 6 \\
\hline Luan & 0.77 & 3 & -0.03 & 7 & -1.58 & 16 & 0.45 & 6 & 0.05 & 7 \\
\hline Maanshan & -0.88 & 16 & -0.30 & 11 & 2.08 & 1 & 0.07 & 8 & -0.16 & 8 \\
\hline Tongling & -0.33 & 9 & -1.18 & 16 & 0.34 & 5 & 2.31 & 1 & -0.21 & 9 \\
\hline Bengbu & -0.50 & 12 & -0.11 & 8 & 0.40 & 4 & -0.88 & 13 & -0.28 & 10 \\
\hline Huainan & -0.21 & 7 & -0.36 & 12 & -0.43 & 11 & 0.05 & 9 & -0.29 & 11 \\
\hline Chuzhou & -0.02 & 6 & -0.82 & 14 & -0.32 & 10 & -0.28 & 11 & -0.38 & 12 \\
\hline Huaibei & -0.72 & 15 & -0.99 & 15 & 0.10 & 6 & 0.88 & 3 & -0.43 & 13 \\
\hline Suzhou & -0.48 & 11 & -0.28 & 10 & -0.49 & 12 & -0.95 & 14 & -0.46 & 14 \\
\hline Bozhou & -0.47 & 10 & -0.14 & 9 & -0.61 & 13 & -1.49 & 15 & -0.48 & 15 \\
\hline Fuyang & 0.01 & 5 & -0.76 & 13 & -0.83 & 14 & -1.53 & 16 & -0.54 & 16 \\
\hline
\end{tabular}


Maanshan, Wuhu, Lu'an, Xuancheng, Anqing and Chizhou are the areas with weak tourism industry potential, and the tourism industry potential of the six places ranks the middle and upper position in Anhui Province. Ma'anshan ranks first in F3 factor score, with good economy and high per capita disposable income. However, its development is restricted by scarce tourism resources. The living quality and urban economic environment of Wuhu residents are good, but it is in the transition stage and faces huge challenges (Li \& Chen, 2018). The tourism resources of Lu'an and Xuancheng are sufficient, but the comprehensive economic strength is not strong, which leads to the general performance of tourism industry potential. Anqing has a large number of A-level and above scenic spots, rich tourism resources and deep tourism culture, but the single index is not significant, and the development potential of the tourism industry is moderate. Chizhou single index is not significant, the development potential of tourism is general.

The regions with weak tourism industry potential are Huaibei, Tongling, Bengbu, Huainan, Bozhou, Suzhou, Fuyang and Chuzhou, and the comprehensive scores of tourism industry potential are all negative. They are the regions with low tourism development level. These eight regions are characterized by lack of tourism resources, weak economic competitiveness and imperfect tourism infrastructure, which restrict the development of tourism in the eight regions and lead to low tourism potential.

\section{Epilogue}

In this paper, from the perspective of tourism potential of Anhui Province, the comprehensive evaluation system of tourism potential of Anhui Province is established by using the methods of systematic cluster analysis and factor analysis (Zhu et al., 2020; Gu et al., 2020), and the development of tourism in Anhui Province is evaluated reasonably, and the result is that the development of tourism in Anhui Province is unbalanced and still needs to be improved. Among them, the tourism development of Hefei is the best, but the tourism development of Huaibei, Tongling, Bengbu, Huainan, Bozhou, Suzhou, Fuyang and Chuzhou is relatively backward, and the development of regional level is unbalanced. The unbalanced development of regional tourism will not only affect the overall development of Anhui Province, but also further expand the regional differences in the long run, and cause some environmental pressure to the regions with developed tourism, which is not conducive to the effective allocation of environmental resources. In the future, we should pay more attention to the balance of the 16 cities' tourism development in Anhui Province, the government should introduce corresponding policies to encourage urban areas with less tourism resources and insufficient driving force to increase investment in tourism, fully tap the tourism development potential of Anhui Province, focus on cultivating areas with greater development potential, increase investment in tourism in backward areas, and build an optimized and balanced regional tour- 
ism system, so as to promote the rapid development of the province's economy and enhance Anhui's position in China.

\section{Conflicts of Interest}

The authors declare no conflicts of interest regarding the publication of this paper.

\section{References}

Cao, N., \& Guo, S. (2005). The Theoretical Basis and Practical Way of Improving Urban Tourism Competitiveness-Taking Liaoning Province as an Example. Journal of Bohai University (Philosophy and Social Sciences Edition), No. 5, 95-98.

Deng, S. C. (2020). Measurement and Spatial Distribution Pattern of Tourism Destination Competitiveness in Chongqing County: A Study Based on Principal Component Analysis and Cluster Analysis. Journal of Xinjiang University of Finance and Economics, No. 2, 53-62.

Dong, Y. C., \& Wu, J. (2016). Comparative Study on Tourism Competitiveness of Vice Provincial Cities in China. Journal of Shandong Normal University (Natural Science Edition), 31, 103-107.

Fang, S., \& Lan, Y. B. (2017). Evaluation of Urban Tourism Competitiveness of Ecological Culture Tourism Circle in Western Hubei Based on SPSS. Journal of Hubei University of Arts and Science, 38, 50-55.

Gu, B. T., Zhu, J. M., \& Huang, T. L. (2020). Research on Stock Investment Value of Science and Technology Innovation Board Based on Factor Analysis and Cluster Analysis. Journal of Jilin Agricultural Science and Technology College, 29, 44-49.

Li, N., \& Chen, X. Q. (2018). A Study on the Evaluation of Fujian City's Tourism Competitiveness from the Perspective of Tourism Economics. Journal of Wuyi University, 37, 85-90.

Luo, N., Chen, L. D., Lu, S. B., Peng, Y., Li, Z., \& Hu, Z. (2020). Reliability Evaluation of Distribution Network Operation Based on Cluster Analysis and Improved Grey Relation. Journal of Wuhan University (Engineering Science), 53, 636-642.

Qu, N. (2016). Study on Evaluation and Promotion of Tourism Competitiveness in Chongqing Area of Qinba Mountains. Chongqing: Southwest University.

Sun, J. (2014). Research on Regional Differences of Tourism Economic Development Potential in Anhui. Hefei: Anhui University.

Zhu, J. M., Lu, M. X., \& Xing, Z. B. (2020). Empirical Research on the Development Potential of Anhui Cargo Transportation Insurance Based on Factor Analysis. Journal of Ningxia University (Natural Science Edition), 41, 134-139. 